\title{
M/M/1 Retrial Queueing System with Loss and Feedback under Pre-Emptive Priority Service
}

\author{
G.AYYAPPAN \\ PONDICHERRY ENGINEERING \\ COLLEGE \\ PONDICHERRY \\ INDIA
}

\author{
A.MUTHU GANAPATHI \\ SUBRAMANIAN \\ TAGORE ARTS COLLEGE \\ PONDICHERRY \\ INDIA
}

\author{
GOPAL SEKAR \\ TAGORE ARTS COLLEGE \\ LAWSPET \\ PONDICHERRY \\ INDIA
}

\begin{abstract}
Consider a single server retrial queueing system with loss and feedback under Pre-emptive priority service in which two types of customers arrive in a Poisson process with arrival rate $\lambda_{1}$ for low priority customers and $\lambda_{2}$ for high priority customers. These customers are identified as primary calls. The service times follow an exponential distribution with parameters $\mu_{1}$ and $\mu_{2}$ for both types of customers respectively. The retrial, loss and feedback are introduced for low priority customers only. Let $\mathrm{k}$ be the maximum number of waiting spaces for high priority customers in front of the service station. The high priorities customers will be governed by the Pre-emptive priority principle. The access from the orbit to the service facility is governed by the classical retrial policy. This model is solved by using Matrix geometric Technique. Numerical study have been done for Analysis of Mean number of low priority customers in the orbit (MNCO), Mean number of high priority customers in the queue (MPQL), Truncation level (OCUT), probability of server free and probabilities of server busy with low, high priority customers for various values of $\lambda_{1}, \lambda_{2}$, $\mu_{1}, \mu_{2}, \mathrm{p}, \mathrm{q}, \sigma$ and $\mathrm{k}$ in elaborate manner and also various particular cases of this model have been discussed.
\end{abstract}

\section{Keywords}

Retrial queues - pre-emptive priority service - loss and feedback Matrix Geometric Method - classical retrial policy

\section{INTRODUCTION}

Queueing systems in which arriving customers who find all servers and waiting positions (if any) occupied may retry for service after a period of time is called Retrial queues. The detailed information, survey of retrial queues and bibliographical information have been obtained from Artalejo (1990a, 1990b, 2010) and Falin and Templeton (1997). Because of the complexity of the retrial queueing models, analytic results are generally difficult to obtain. There are a great number of numerical and approximations methods are available, in this paper we will place more emphasis on the solutions by Matrix geometric method discussed by M.F. Neuts (1981), Latouche. G and V. Ramaswamy (1999). Formulation of queues with feedback mechanism was first introduced by Takacs (1963). Choi and Kulkarni (1992) have studied M/G/1 retrial queue with feedback.
Choi et al. (1998) have investigated M/M/c retrial queue with geometric loss and feedback. Krishna kumar et al. (2002) have studied M/G/1 retrial queue with feedback and starting failures. Kalyanaraman and Srinivasan (2004) studied M/G/1 retrial queueing system with two types of calls and geometric loss. Lee. Y.W (2005) has studied M/G/1 feedback retrial queue with two types of customers. Choi and Park (1990) investigated an $\mathrm{M}_{1}, \mathrm{M}_{2} / \mathrm{G} / \mathrm{l}$ retrial queue with two types of calls, infinite priority queue (or infinite waiting room) for Type I calls and infinite retrial group for Type II and derived the joint generating function of the number of calls in the two groups and the mean queue lengths by supplementary variable methods. Falin, Artalejo and Martin (1993) extended Choi and Park's results to the case where two types of calls may have different service time distributions. Choi and Chang (1999) have studied the Single Server Retrial Queues with Priority Calls. Artalejo J.R and et al (2001) have studied stationary analysis of retrial queues with pre-emptive repeated attempts.

\section{MODEL DESRIPTION}

Consider a single server retrial queueing system with loss and feedback under Pre-emptive priority service in which two types of customers arrive in a Poisson process with arrival rate $\lambda_{1}$ for low priority customers and $\lambda_{2}$ for high priority customers. These customers are identified as primary calls. The service times follow an exponential distribution with parameters $\boldsymbol{\mu}_{\mathbf{1}}$ and $\boldsymbol{\mu}_{\mathbf{2}}$ for both types of customers. The retrial, loss and feedback are introduced for low priority customers only. This concept is recently (2009) discussed by K. Farahmand and T. Li for single server retrial queueing by analytic method. Let $\mathrm{k}$ be the maximum number of waiting spaces for high priority customers in front of the service station.

\subsection{Description of loss and feedback}

The concepts loss and feedback are introduced for low priority customers only. If the server is free at the time of the arrival of low priority customer, then the arriving call begins to be served immediately by the server. After completion of the service, if the low priority customer dissatisfied then he may join the orbit with probability q and with probability (1-q) he leaves the system. This 
is called feedback in queueing theory. If the server is busy at the time of the arrival of low priority customer, then due to impatient this low priority customer may or may not join the orbit. This is called loss in queueing theory. We assume that $\mathrm{p}$ is the probability that the low priority customer joins the orbit and (1-p) is the probability that he leaves the system without getting service (due to impatient).

If the server is free at the time of the arrival of high priority customer, then the arriving call begins to be served immediately by the server and high priority customer leaves the system after service completion. If the server is busy then the low priority arriving customer goes to orbit with probability $\mathbf{p}$ and becomes a source of repeated calls. The pool of sources of repeated calls may be viewed as a sort of queue. Every such source produces a Poisson process of repeated calls with intensity $\boldsymbol{\sigma}$. If an incoming repeated call finds the server free, then it is served and leaves the system after service, while the source which produced this repeated call disappears.

If any one of the waiting spaces is occupied by the high priority customers then the low priority customers (as a primary call) can not enter into service station and goes to orbit with probability $p$. If the server is busy and there are some waiting spaces then the high priority customer can enter into the service station and waits for his service. If there are no waiting spaces then the high priority customers can not enter into the service station and will be lost for the system. Otherwise, the system state does not change.

\subsection{Priority Rule}

If the server is engaging with low priority customer and at that time the higher priority customer enters then the high priority customer will get service immediately and the low priority customer who is in service goes to orbit without completion of his service. This type of priority service is called the Pre-emptive priority service.

\subsection{Retrial Policy:}

Most of the queueing system with repeated attempts assume that each customer in the retrial group seeks service independently of each other after a random time exponentially distributed with rate $\boldsymbol{\sigma}$ so that the probability of repeated attempt during the interval $(t, t+\Delta \mathrm{t})$ given that there were $\mathrm{n}$ customers in orbit at time $t$ is no $\Delta \mathbf{t}+\mathbf{O}(\Delta \mathbf{t})$. This discipline for access for the server from the retrial group is called classical retrial rate policy. The input flow of primary calls (low and high), interval between repetitions and service times are mutually independent.

\section{MATRIX GEOMETRIC METHOD}

Let $\mathrm{N}(\mathrm{t})$ be the random variable which represents the number of low priority customers in the orbit at time $t$ and $H(t)$ be the random variable which represents the number of high priority customers in the queue (in front of the service station) at time $t$ and $\mathrm{S}(\mathrm{t})$ represents the server state at time $\mathrm{t}$. The random process

is described as $\{<\mathrm{N}(\mathrm{t}), \mathrm{H}(\mathrm{t}), \mathrm{S}(\mathrm{t}) \quad>/ \mathrm{N}(\mathrm{t})=0,1,2,3,4 \ldots$; $\mathrm{H}(\mathrm{t})=0,1,2,3 \ldots \mathrm{k} ; \mathrm{S}(\mathrm{t})=0,1,2\}$.

$\mathrm{S}(\mathrm{t})=0$ if the server is idle at time $\mathrm{t}$
$\mathrm{S}(\mathrm{t})=1$ if the server is busy with low priority customer at time $\mathrm{t}$ $\mathrm{S}(\mathrm{t})=2$ if the server is busy with high priority customer at time $\mathrm{t}$ The possible state spaces are

$\{(\mathbf{u}, \mathbf{v}, \mathbf{w}) / \mathbf{u}=\mathbf{0}, 1,2,3, \ldots ; \mathbf{v}=\mathbf{0} ; \mathbf{w}=\mathbf{0}, 1,2\} \bigcup$

$\{(\mathrm{u}, \mathrm{v}, \mathrm{w}) / \mathrm{u}=0,1,2,3, \ldots ; \mathrm{v}=1,2,3 \ldots \mathrm{k} ; \mathrm{w}=1,2\}$

The infinitesimal generator matrix $\mathbf{Q}$ is given below

$$
Q=\left(\begin{array}{llllll}
\mathrm{A}_{00} & \mathrm{~A}_{0} & \mathrm{O} & \mathrm{O} & \mathrm{O} & \cdots \\
\mathrm{A}_{10} & \mathrm{~A}_{11} & \mathrm{~A}_{0} & \mathrm{O} & \mathrm{O} & \cdots \\
\mathrm{O} & \mathrm{A}_{21} & \mathrm{~A}_{22} & \mathrm{~A}_{0} & \mathrm{O} & \cdots \\
\mathrm{O} & \mathrm{O} & \mathrm{A}_{32} & \mathrm{~A}_{33} & \mathrm{~A}_{0} & \cdots \\
\cdots & \cdots & \cdots & \cdots & \cdots & \cdots
\end{array}\right)
$$

\section{Notations}

$$
\begin{array}{lll}
\mathbf{T}_{1}=-\left(\lambda_{1}+\lambda_{2}\right) & \mathbf{T}_{2}=-\left(\mathrm{p} \lambda_{1}+\lambda_{2}+\mu_{1}\right) & \mathbf{T}_{3}=-\left(\mathrm{p} \lambda_{1}+\lambda_{2}+\mu_{2}\right) \\
\mathbf{T}_{4}=-\left(\mathrm{p} \lambda_{1}+\mu_{2}\right) & \mathbf{T}_{5}=-\left(\mathrm{n} \sigma+\lambda_{1}+\lambda_{2}\right) & \mathbf{T}_{6}=-\left(\mathrm{M} \sigma+\lambda_{1}+\lambda_{2}\right) \\
\mathbf{T}_{7}=-\left(\lambda_{2}+\mu_{2}\right) & \mathbf{T}_{8}=-\left(\mathrm{p} \lambda_{1}+\lambda_{2}+(\mathbf{1}-\mathrm{q}) \mu_{1}\right)
\end{array}
$$

$\mathbf{A}_{00}, \mathbf{A}_{01}, \mathbf{A}_{\mathrm{nn}-\mathbf{1}}, \mathbf{A}_{\mathrm{nn}}, \mathbf{A}_{\mathrm{nn}+\mathbf{1}}$ are square matrices order $\mathbf{k}+\mathbf{3}$.

The matrix $\mathrm{A}_{00}$ is described as

$$
\left(\begin{array}{llllllll}
\mathrm{T}_{1} & \lambda_{1} & \lambda_{2} & 0 & 0 & \ldots & 0 & 0 \\
(1-\mathrm{q}) \mu_{1} & \mathrm{~T}_{2} & 0 & 0 & 0 & \ldots & 0 & 0 \\
\mu_{2} & 0 & \mathrm{~T}_{3} & \lambda_{2} & 0 & \ldots & 0 & 0 \\
0 & 0 & \mu_{2} & \mathrm{~T}_{3} & \lambda_{2} & \ldots & 0 & 0 \\
\ldots & \ldots & \ldots & \ldots & \ldots & \ldots & \ldots & \ldots \\
0 & 0 & 0 & 0 & 0 & \ldots & \mathrm{T}_{3} & \lambda_{2} \\
0 & 0 & 0 & 0 & 0 & \ldots & \mu_{2} & \mathrm{~T}_{4}
\end{array}\right)
$$

$A_{n, n-1}=\left(a_{i j}\right)$ for $n=1,2,3, \ldots$

where $a_{i j}=n \sigma$ if $(i=1$ and $j=2)$

$$
=0 \quad \text { otherwise }
$$

$$
\begin{aligned}
& \mathbf{A}_{\mathbf{0}}=\mathbf{A}_{\mathbf{n}, \mathbf{n}+\mathbf{1}}=\left(\mathbf{a}_{\mathbf{i j}}\right) \text { for } \mathrm{n}= \\
& \text { where } \quad \begin{aligned}
\mathbf{a}_{\mathbf{i j}} & =\mathrm{p} \lambda_{1} \quad \text { if } \mathrm{i}=\mathrm{j} \text { and } \mathrm{i}=2,3,4, \ldots, \mathrm{k}+3 \\
& =q \mu_{1} \quad \text { if } \mathrm{i}=2 \text { and } \mathrm{j}=1 \\
& =\lambda_{2} \quad \text { if } \mathrm{i}=2 \text { and } \mathrm{j}=3 \\
& =0 \quad \text { otherwise. }
\end{aligned}
\end{aligned}
$$


The matrix $A_{n n}$ is described as

$$
\left(\begin{array}{cccccccc}
\mathbf{T}_{\mathbf{5}} & \boldsymbol{\lambda}_{\mathbf{1}} & \boldsymbol{\lambda}_{\mathbf{2}} & 0 & 0 & \ldots & 0 & 0 \\
(\mathbf{1}-\mathbf{q}) \boldsymbol{\mu}_{1} & \mathrm{~T}_{2} & 0 & 0 & 0 & \ldots & 0 & 0 \\
\mu_{2} & 0 & \mathbf{T}_{3} & \lambda_{2} & 0 & \ldots & 0 & 0 \\
0 & 0 & \mu_{2} & \mathrm{~T}_{3} & \lambda_{2} & \ldots & 0 & 0 \\
\ldots & \ldots & \ldots & \ldots & \ldots & \ldots & \ldots & \ldots \\
0 & 0 & 0 & 0 & 0 & \ldots & \mathrm{T}_{3} & \lambda_{2} \\
0 & 0 & 0 & 0 & 0 & \ldots & \mu_{2} & \mathrm{~T}_{4}
\end{array}\right)
$$

If the capacity of the orbit is finite say $M$ then $A_{M M}$ is described as

$$
\left(\begin{array}{cccccccc}
\mathbf{T}_{\mathbf{6}} & \lambda_{\mathbf{1}} & \lambda_{2} & 0 & 0 & \ldots & 0 & 0 \\
\mu_{1} & -\mu_{1} & 0 & 0 & 0 & \ldots & 0 & 0 \\
\mu_{2} & 0 & \mathbf{T}_{7} & \lambda_{2} & 0 & \ldots & 0 & 0 \\
0 & 0 & \mu_{2} & \mathrm{~T}_{7} & \lambda_{2} & \ldots & 0 & 0 \\
\cdots & \cdots & \cdots & \cdots & \cdots & \ldots & \ldots & \cdots \\
0 & 0 & 0 & 0 & 0 & \ldots & \mathrm{T}_{7} & \lambda_{2} \\
0 & 0 & 0 & 0 & 0 & \ldots & \mu_{2} & -\mu_{2}
\end{array}\right)
$$

Let $\mathbf{X}$ be a steady-state probability vector of $\mathbf{Q}$ and partitioned as

$$
\begin{gathered}
\mathbf{X}=(\mathrm{x}(0), \mathrm{x}(1), \mathrm{x}(2), \ldots \text { and } \mathbf{X} \text { satisfies } \\
\mathbf{X} \mathbf{Q}=\mathbf{0}, \mathbf{X e}=\mathbf{1}
\end{gathered}
$$

where $x(i)=\left(P_{i 00}, P_{i 01}, P_{i 02}, P_{i 12}, P_{i 22} \ldots, P_{i k 2}\right) i=0,1,2,3, \ldots$

\section{DIRECT TRUNCATION METHOD}

In this method one can truncate the system of equations in (1) for sufficiently large value of the number of customers in the orbit, say $M$. That is, the orbit size is restricted to $M$ such that any arriving customer finding the orbit full is considered lost. The value of $\mathrm{M}$ can be chosen so that the loss probability is small. Due to the intrinsic nature of the system in (1) the only choice available for studying $\mathrm{M}$ is through algorithmic methods. While a number of approaches are available for determining the cut-off point, $\mathrm{M}$, the one that seems to perform well (with respect to approximating the system performance measures) is to increase $\mathrm{M}$ until the largest individual change in the elements of $\mathbf{X}$ for successive values is less than $\boldsymbol{\varepsilon}$ a predetermined infinitesimal value.

\section{ANALYSIS OF STEADY STATE PROBABILITIES}

We are applying Direct Truncation Method to find Steady state probability vector $\mathbf{X}$. Let $\mathbf{M}$ denote the cut-off point or Truncation level. The steady state probability vector $\mathbf{X}^{(\mathbf{M})}$ is now partitioned as $\mathbf{X}^{(\mathbf{M})}=(\mathbf{x}(0), \mathbf{x}(1), \mathbf{x}(2), \ldots . . x(\mathbf{M}))$ and $\mathbf{X}^{(\mathbf{M})}$ satisfies

$$
\mathbf{X}^{(\mathbf{M})} \mathbf{Q}=\mathbf{0}, \mathbf{X}^{(\mathbf{M})} \mathbf{e}=\mathbf{1}
$$

where $x(\mathrm{i})=\left(\mathrm{P}_{\mathrm{i} 00}, \mathrm{P}_{\mathrm{i} 01}, \mathrm{P}_{\mathrm{i} 02}, \mathrm{P}_{\mathrm{i} 12}, \mathrm{P}_{\mathrm{i} 22, \ldots} \ldots, \mathrm{P}_{\mathrm{ik} 2}\right) \mathrm{i}=0,1,2,3, \ldots, \mathrm{M}$

The above system of equations is solved by Numerical method such as GAUSS-JORDAN elementary transformation method. Since there is no clear cut choice for M, we may start the iterative process by taking, say $M=1$ and increase it until the individual elements of $\mathbf{X}$ do not change significantly. That is, if $\mathbf{M}^{*}$ denotes the truncation point then

$$
\left\|\mathrm{X}^{\mathrm{M}^{*}}(\mathbf{i})-\mathrm{X}^{\mathrm{M}^{*-1}}(\mathbf{i})\right\|_{\infty}<\varepsilon, \boldsymbol{\varepsilon} \text { is an infinitesimal quantity. }
$$

\section{STABILITY CONDITION}

Theorem :

The inequality $\left(\frac{F p \lambda_{1}}{(1-q) \mu_{1}}\right)<1$ where $\mathbf{F}=\mathbf{1}+\mathbf{x}+\mathbf{x}^{2}+\ldots+\mathbf{x}^{\mathbf{k}+1}$

$\mathbf{x}=\boldsymbol{\lambda}_{2} / \boldsymbol{\mu}_{\mathbf{2}}$, is the necessary and sufficient condition for the system to be stable.

\section{Proof:}

Let $\mathrm{Q}$ be an infinitesimal generator matrix for the queueing system (without retrial)

The stationary probability vector $\mathrm{X}$ satisfying

$$
\begin{aligned}
& X \mathbf{Q}=\mathbf{0} \text { and } \mathbf{X e}=\mathbf{1} \\
& \mathbf{A}_{\mathbf{0}}+\mathbf{R} \mathbf{A}_{\mathbf{1}}+\mathbf{R}^{\mathbf{2}} \mathbf{A}_{\mathbf{2}}=\mathbf{0}, \mathbf{R} \text { is the Rate Matrix }
\end{aligned}
$$

The system is stable if $\mathrm{sp}(\mathrm{R})<1$

$\mathrm{R}$ satisfies $\operatorname{sp}(\mathrm{R})<1$ if and only if $\quad \boldsymbol{\Pi \mathbf { A } _ { 0 }} \mathbf{e}<\boldsymbol{\Pi \mathbf { A } _ { 2 }} \mathbf{e}$ 


$$
\Pi \mathrm{A}=0 \text { and } \Pi \mathrm{e}=1
$$$$
A=A_{0}+A_{1}+A_{2}
$$

$A_{0}, A_{1}, A_{2}$ are square matrices of order $k+2$ and

$$
\begin{aligned}
\mathrm{A}_{0}=\left(\mathbf{a}_{\mathrm{ij}}\right) \text { where } \mathbf{a}_{\mathrm{ij}} & =\mathrm{p} \lambda_{1} \quad \text { if } \mathrm{i}=\mathrm{j} \text { and } \mathrm{i}=1,2,3,4, \ldots, \mathrm{k}+2 \\
= & \lambda_{2} \quad \text { if } \mathrm{i}=1 \text { and } \mathrm{j}=2 \\
= & 0 \quad \text { otherwise. } \\
\mathrm{A}_{2}=\left(\mathrm{a}_{\mathrm{ij}}\right) \text { where } \quad \mathrm{a}_{\mathrm{ij}} & =(1-\mathrm{q}) \mu_{1} \quad \text { if } \mathrm{i}=1 \text { and } \mathrm{j}=1 \\
& =\mu_{2} \quad \text { if } \mathrm{i}=2 \text { and } \mathrm{j}=1 \\
& =0 \quad \text { otherwise }
\end{aligned}
$$

The matrix $A_{1}$ is described as

$$
\left(\begin{array}{ccccccc}
\mathbf{T}_{\mathbf{8}} & \mathbf{0} & \mathbf{0} & \mathbf{0} & \ldots & \mathbf{0} & \mathbf{0} \\
\mathbf{0} & \mathbf{T}_{3} & \boldsymbol{\lambda}_{2} & \mathbf{0} & \ldots & \mathbf{0} & \mathbf{0} \\
\mathbf{0} & \boldsymbol{\mu}_{2} & \mathbf{T}_{3} & \boldsymbol{\lambda}_{2} & \ldots & \mathbf{0} & \mathbf{0} \\
\mathbf{0} & \mathbf{0} & \boldsymbol{\mu}_{2} & \mathbf{T}_{3} & \ldots & \boldsymbol{\lambda}_{2} & \mathbf{0} \\
\cdots & \ldots & \ldots & \ldots & \ldots & \ldots & \\
\mathbf{0} & \mathbf{0} & \mathbf{0} & \boldsymbol{\mu}_{2} & \ldots & \mathbf{T}_{3} & \boldsymbol{\lambda}_{2} \\
\mathbf{0} & \mathbf{0} & \mathbf{0} & \mathbf{0} & \ldots & \boldsymbol{\mu}_{2} & \mathbf{T}_{6}
\end{array}\right)
$$

By substituting $\mathrm{A}_{0}, \mathrm{~A}_{1}, \mathrm{~A}_{2}$ in equation,(5), we get

$$
\begin{gathered}
\pi_{\mathrm{i}}=\mathrm{x}^{\mathrm{i}} \pi_{0} \quad \mathrm{i}=1,2,3 \ldots, \mathrm{k}+1 \\
\pi_{0}+\pi_{1}+\pi_{2}+\pi_{3}+\pi_{4}+\pi_{5} \ldots \ldots+\pi_{\mathrm{k}-1}+\pi_{\mathrm{k}}+\pi_{\mathrm{k}+1}=1
\end{gathered}
$$

by substituting $\pi_{\mathrm{i}}$ values in the above equation we get

$$
\pi_{0}=1 / F \text { where } F=1+x+x^{2}+\ldots+x^{k+1}
$$

From (4)

$$
\left(\frac{p \lambda_{1}}{(1-q) \mu_{1}}\right)<\pi_{0}
$$

by substituting $\pi_{0}$ we get

$$
\left(\frac{F p \lambda_{1}}{(1-q) \mu_{1}}\right)<1
$$

The inequality $\left(\frac{F p \lambda_{1}}{(1-q) \mu_{1}}\right)<1$ is also a sufficient condition for the retrial queueing system to be stable. Let $\mathrm{Q}_{\mathrm{n}}$ be the number of customers in the orbit after departure $n^{\text {th }}$ customer from the

service station. We first prove the embedded Markov chain $\left\{\mathrm{Q}_{\mathrm{n}}, \mathrm{n} \geq 0\right\}$ is ergodic if $\left(\frac{F p \lambda_{1}}{(1-q) \mu_{1}}\right)<1$ is readily to see that $\{\mathrm{Qn}, \mathrm{n} \geq 0\}$ is irreducible and aperiodic. It remains to be proved that $\left\{Q_{n}, n \geq 0\right\}$ is positive recurrent. The irreducible and aperiodic Markov chain $\left\{Q_{n}, n \geq 0\right\}$ is positive recurrent if $\left|\psi_{i}\right|<\infty$ for all $i$ and $\quad \lim _{\mathrm{i} \rightarrow \infty}$ sup $\psi_{\mathrm{i}}<0$ where

$$
\begin{aligned}
& \boldsymbol{\psi}_{\mathbf{i}}=\mathbf{E}\left(\mathbf{Q}_{\mathbf{n}+\mathbf{1}}-\mathbf{Q}_{\mathbf{n}} / \mathbf{Q}_{\mathbf{n}}=\mathbf{i}\right) \text { for } \mathrm{i}=0,1,2,3,4,5 \ldots \\
& \boldsymbol{\psi}_{\mathbf{i}}=\left(\frac{F p \lambda_{1}}{(1-q) \mu_{1}}\right)-\mathbf{k} \boldsymbol{\sigma} /\left(\boldsymbol{\lambda}_{\mathbf{1}}+\lambda_{\mathbf{2}}+\mathbf{k} \boldsymbol{\sigma}\right)
\end{aligned}
$$

if $\left(\frac{F p \lambda_{1}}{(1-q) \mu_{1}}\right)<1$, then $\left|\psi_{\mathrm{i}}\right|<\infty$ for all $\mathrm{i}$ and $\lim _{\mathrm{i} \rightarrow \infty} \sup \psi_{\mathrm{i}}$ $<0$. Therefore the embedded Markov chain $\left\{Q_{n}, n \geq 0\right\}$ is ergodic. If $\mathrm{K} \rightarrow \infty$ then the above stability condition becomes

$$
\left(\frac{p \lambda_{1}}{(1-q) \mu_{1}}+\frac{\lambda_{2}}{\mu_{2}}\right)<1 \text {. }
$$

\begin{tabular}{|c|c|}
\hline MNCO & Mean Number of Customers in the Orbit \\
\hline MPQL & $\begin{array}{l}\text { : Mean Number of high priority customers in front of } \\
\text { the service station }\end{array}$ \\
\hline $\mathrm{P}_{0}$ & : Probability that the server is idle \\
\hline $\mathrm{P}_{1}$ & Probability that the server is busy with low priority \\
\hline
\end{tabular}

\section{SPECIAL CASES}

1. This model becomes Single Server Retrial queueing system with pre-emptive priority service if $\mathrm{q} \rightarrow 0$ and $\mathrm{p} \rightarrow 1$.

2. This model becomes Single Server Retrial queueing system if $\left(\boldsymbol{\lambda}_{2} \rightarrow 0\right),\left(\boldsymbol{\mu}_{2} \rightarrow \infty\right), \mathrm{q} \rightarrow 0$ and $\mathrm{p} \rightarrow 1$

3. This model becomes Single Server Standard Queueing System if $\lambda_{2} \rightarrow 0, \boldsymbol{\mu}_{2} \rightarrow \infty, \mathrm{q} \rightarrow 0, \mathrm{p} \rightarrow 1$ and $\sigma \rightarrow \infty$

\section{SYSTEM PERFORMANCE MEASURES}

In this section we will list some important performance measures along with their formulas. These measures are used to bring out the qualitative behaviour of the queueing model under study. Numerical study has been dealt in very large scale to study the following measures. We define, 
customers

$\mathrm{P}_{2} \quad$ : Probability that the server is busy with high priority customers

a) Probability mass function of server state

Prob (The server is idle $)=\sum_{i=0}^{\infty} p(i, 0,0)$

Prob (The server is busy with low priority customer)

$$
=\sum_{i=0}^{\infty} p(i, 0,1)
$$

Prob (The server is busy with high priority customer)

$$
=\sum_{i=0}^{\infty} \sum_{j=0}^{k} p(i, j, 2)
$$

b) Probability mass function of number of customers in the

orbit

Prob ( $\mathrm{n}$ customers in the orbit)

$$
=\sum_{j=0}^{k} p(n, j, 2)+\mathrm{p}(\mathrm{n}, 0,0)+\mathrm{p}(\mathrm{n}, 0,1)
$$

c) Probability mass function of number of high priority customers in the queue.

Prob (No customers in the high priority queue)

$$
=\sum_{i=0}^{\infty} \sum_{l=0}^{2} p(i, 0, l)
$$

Prob ( $\mathrm{j}$ customers in the high priority queue)

$$
=\sum_{i=0}^{\infty} p(i, j, 2)
$$

d) Mean number of high priority customers in the queue

$$
\mathrm{MPQL}=\sum_{j=1}^{k} j\left(\sum_{i=0}^{\infty} p(i, j, 2)\right)
$$

e) Mean number of low priority customers in the orbit

$$
\mathrm{MNCO}=\left(\sum_{i=0}^{\infty} i\left(\sum_{j=0}^{k} p(i, j, 2)+\mathrm{p}(\mathrm{i}, 0,0)+\mathrm{p}(\mathrm{i}, 0,1)\right)\right)
$$

f) The probability that the orbiting customer (low) is blocked Blocking Probability

$$
=\sum_{i=1}^{\infty} \sum_{j=0}^{k} p(i, j, 2)+\sum_{i=1}^{\infty} p(i, 0,1)
$$

g) The probability that the low priority customer gets service

$$
\text { immediately }=\sum_{i=0}^{\infty} p(i, 0,0)
$$

h) The Probability that the high priority customer gets service immediately

$$
=\sum_{i=0}^{\infty} p(i, 0,1)+\sum_{i=0}^{\infty} p(i, 0,0)
$$

i) The probability that the high priority customer gets into system immediately

$$
=\sum_{i=0}^{\infty} \sum_{j=0}^{k-1} p(i, j, 2)+\sum_{i=0}^{\infty} p(i, 0,1)+\sum_{i=0}^{\infty} p(i, 0,0)
$$

\section{NUMERICAL STUDY}

Table I, Table II, Table III, Table IV show the impact of retrial rate over the system. Mean number of customers in the orbit decreases as $\sigma$ increases. When $\sigma$ is large, values of tables show that this retrial model becomes standard queueing model. Mean number high priority customers (MPQL) increases as $\mathrm{k}$ increases

Table I: Mean number of customers in the orbit and Mean queue length of high Priority queue for $\lambda_{1}=10 \quad \lambda_{2}=5 \quad \mu_{1}=20$ $\mu_{2}=25 \mathrm{p}=0.8 \mathrm{q}=0.2$ and $\mathrm{k}=2$ and various values of $\sigma$

\begin{tabular}{|c|c|c|c|c|c|c|}
\hline$\sigma$ & Ocut & $\mathrm{P}_{0}$ & $\mathrm{P}_{1}$ & $\mathrm{P}_{2}$ & $\mathrm{MNCO}$ & $\mathrm{MPQL}$ \\
\hline 10 & 51 & 0.2678 & 0.5335 & 0.1987 & 4.6749 & 0.0449 \\
\hline 20 & 46 & 0.2678 & 0.5335 & 0.1987 & 3.0833 & 0.0449 \\
\hline 30 & 44 & 0.2678 & 0.5335 & 0.1987 & 2.5527 & 0.0449 \\
\hline 40 & 43 & 0.2678 & 0.5335 & 0.1987 & 2.2875 & 0.0449 \\
\hline 50 & 43 & 0.2678 & 0.5335 & 0.1987 & 2.1283 & 0.0449 \\
\hline 60 & 42 & 0.2678 & 0.5335 & 0.1987 & 2.0222 & 0.0449 \\
\hline 70 & 42 & 0.2678 & 0.5335 & 0.1987 & 1.9464 & 0.0449 \\
\hline 80 & 42 & 0.2678 & 0.5335 & 0.1987 & 1.8896 & 0.0449 \\
\hline 90 & 42 & 0.2678 & 0.5335 & 0.1987 & 1.8453 & 0.0449 \\
\hline 100 & 41 & 0.2678 & 0.5335 & 0.1987 & 1.8100 & 0.0449 \\
\hline 200 & 41 & 0.2678 & 0.5335 & 0.1987 & 1.6508 & 0.0449 \\
\hline 300 & 41 & 0.2678 & 0.5335 & 0.1987 & 1.5978 & 0.0449 \\
\hline 400 & 40 & 0.2678 & 0.5335 & 0.1987 & 1.5712 & 0.0449 \\
\hline 500 & 40 & 0.2678 & 0.5335 & 0.1987 & 1.5553 & 0.0449 \\
\hline 600 & 40 & 0.2678 & 0.5335 & 0.1987 & 1.5447 & 0.0449 \\
\hline
\end{tabular}




\begin{tabular}{|l|l|l|l|l|l|l|}
700 & 40 & 0.2678 & 0.5335 & 0.1987 & 1.5371 & 0.0449 \\
\hline 800 & 40 & 0.2678 & 0.5335 & 0.1987 & 1.5314 & 0.0449 \\
\hline 900 & 40 & 0.2678 & 0.5335 & 0.1987 & 1.5270 & 0.0449 \\
\hline 1000 & 40 & 0.2678 & 0.5335 & 0.1987 & 1.5235 & 0.0449 \\
\hline 2000 & 40 & 0.2678 & 0.5335 & 0.1987 & 1.5076 & 0.0449 \\
\hline 3000 & 40 & 0.2678 & 0.5335 & 0.1987 & 1.5023 & 0.0449 \\
\hline 4000 & 40 & 0.2678 & 0.5335 & 0.1987 & 1.4996 & 0.0449 \\
\hline 5000 & 40 & 0.2678 & 0.5335 & 0.1987 & 1.4980 & 0.0449 \\
\hline 6000 & 40 & 0.2678 & 0.5335 & 0.1987 & 1.4970 & 0.0449 \\
\hline 7000 & 40 & 0.2678 & 0.5335 & 0.1987 & 1.4962 & 0.0449 \\
\hline 8000 & 40 & 0.2678 & 0.5335 & 0.1987 & 1.4956 & 0.0449 \\
\hline 9000 & 40 & 0.2678 & 0.5335 & 0.1987 & 1.4952 & 0.0449 \\
\hline
\end{tabular}

\begin{tabular}{|c|c|c|c|c|c|c|}
800 & 41 & 0.2667 & 0.5333 & 0.1999 & 1.5500 & 0.0497 \\
\hline 900 & 41 & 0.2667 & 0.5333 & 0.1999 & 1.5456 & 0.0497 \\
\hline 1000 & 41 & 0.2667 & 0.5333 & 0.1999 & 1.5421 & 0.0497 \\
\hline 2000 & 41 & 0.2667 & 0.5333 & 0.1999 & 1.5261 & 0.0497 \\
\hline 3000 & 41 & 0.2667 & 0.5333 & 0.1999 & 1.5207 & 0.0497 \\
\hline 4000 & 41 & 0.2667 & 0.5333 & 0.1999 & 1.5181 & 0.0497 \\
\hline 5000 & 41 & 0.2667 & 0.5333 & 0.1999 & 1.5165 & 0.0497 \\
\hline 6000 & 41 & 0.2667 & 0.5333 & 0.1999 & 1.5154 & 0.0497 \\
\hline 7000 & 41 & 0.2667 & 0.5333 & 0.1999 & 1.5146 & 0.0497 \\
\hline 8000 & 41 & 0.2667 & 0.5333 & 0.1999 & 1.5141 & 0.0497 \\
\hline 9000 & 41 & 0.2667 & 0.5333 & 0.1999 & 1.5136 & 0.0497 \\
\hline
\end{tabular}

Table II: Mean number of customers in the orbit and Mean queue length of high Priority queue for $\lambda_{1}=10$ $\lambda_{2}=5 \quad \mu_{1}=20 \quad \mu_{2}=25 \quad p=0.8 \quad q=0.2$ and $\mathrm{k}=4$ and various values of $\sigma$

\begin{tabular}{|c|c|c|c|c|c|c|}
\hline$\sigma$ & Ocut & $\mathrm{P}_{0}$ & $\mathrm{P}_{1}$ & $\mathrm{P}_{2}$ & $\mathrm{MNCO}$ & $\mathrm{MPQL}$ \\
\hline 10 & 51 & 0.2667 & 0.5333 & 0.1999 & 4.7094 & 0.0497 \\
\hline 20 & 46 & 0.2667 & 0.5333 & 0.1999 & 3.1097 & 0.0497 \\
\hline 30 & 45 & 0.2667 & 0.5333 & 0.1999 & 2.5765 & 0.0497 \\
\hline 40 & 44 & 0.2667 & 0.5333 & 0.1999 & 2.3099 & 0.0497 \\
\hline 50 & 43 & 0.2667 & 0.5333 & 0.1999 & 2.1499 & 0.0497 \\
\hline 60 & 43 & 0.2667 & 0.5333 & 0.1999 & 2.0433 & 0.0497 \\
\hline 70 & 42 & 0.2667 & 0.5333 & 0.1999 & 1.9671 & 0.0497 \\
\hline 80 & 42 & 0.2667 & 0.5333 & 0.1999 & 1.9100 & 0.0497 \\
\hline 90 & 42 & 0.2667 & 0.5333 & 0.1999 & 1.8655 & 0.0497 \\
\hline 100 & 42 & 0.2667 & 0.5333 & 0.1999 & 1.8300 & 0.0497 \\
\hline 200 & 41 & 0.2667 & 0.5333 & 0.1999 & 1.6700 & 0.0497 \\
\hline 300 & 41 & 0.2667 & 0.5333 & 0.1999 & 1.6167 & 0.0497 \\
\hline 400 & 41 & 0.2667 & 0.5333 & 0.1999 & 1.5900 & 0.0497 \\
\hline 500 & 41 & 0.2667 & 0.5333 & 0.1999 & 1.5740 & 0.0497 \\
\hline 600 & 41 & 0.2667 & 0.5333 & 0.1999 & 1.5634 & 0.0497 \\
\hline 700 & 41 & 0.2667 & 0.5333 & 0.1999 & 1.5558 & 0.0497 \\
\hline
\end{tabular}

Table III: Mean number of customers in the orbit and Mean queue length of high Priority queue for $\lambda_{1}=10 \quad \lambda_{2}=5 \quad \mu_{1}=20 \quad \mu_{2}=25 \quad p=0.8 \quad q=0.2 \quad k=6$ and various values of $\sigma$

\begin{tabular}{|c|c|c|c|c|c|c|}
\hline$\sigma$ & Ocut & $P_{0}$ & $P_{1}$ & $P_{2}$ & MNCO & MPQL \\
\hline 10 & 52 & 0.2667 & 0.5333 & 0.2000 & 4.7110 & 0.0500 \\
\hline 20 & 47 & 0.2667 & 0.5333 & 0.2000 & 3.1110 & 0.0500 \\
\hline 30 & 45 & 0.2667 & 0.5333 & 0.2000 & 2.5777 & 0.0500 \\
\hline 40 & 44 & 0.2667 & 0.5333 & 0.2000 & 2.3110 & 0.0500 \\
\hline 50 & 43 & 0.2667 & 0.5333 & 0.2000 & 2.1511 & 0.0500 \\
\hline 60 & 43 & 0.2667 & 0.5333 & 0.2000 & 2.0444 & 0.0500 \\
\hline 70 & 42 & 0.2667 & 0.5333 & 0.2000 & 1.9682 & 0.0500 \\
\hline 80 & 42 & 0.2667 & 0.5333 & 0.2000 & 1.9111 & 0.0500 \\
\hline 90 & 42 & 0.2667 & 0.5333 & 0.2000 & 1.8666 & 0.0500 \\
\hline 100 & 42 & 0.2667 & 0.5333 & 0.2000 & 1.8311 & 0.0500 \\
\hline 200 & 41 & 0.2667 & 0.5333 & 0.2000 & 1.6711 & 0.0500 \\
\hline 300 & 41 & 0.2667 & 0.5333 & 0.2000 & 1.6177 & 0.0500 \\
\hline 400 & 41 & 0.2667 & 0.5333 & 0.2000 & 1.5911 & 0.0500 \\
\hline
\end{tabular}




\begin{tabular}{|l|l|l|l|l|l|l|}
500 & 41 & 0.2667 & 0.5333 & 0.2000 & 1.5751 & 0.0500 \\
\hline 600 & 41 & 0.2667 & 0.5333 & 0.2000 & 1.5644 & 0.0500 \\
\hline 700 & 41 & 0.2667 & 0.5333 & 0.2000 & 1.5568 & 0.0500 \\
\hline 800 & 41 & 0.2667 & 0.5333 & 0.2000 & 1.5511 & 0.0500 \\
\hline 900 & 41 & 0.2667 & 0.5333 & 0.2000 & 1.5466 & 0.0500 \\
\hline 1000 & 41 & 0.2667 & 0.5333 & 0.2000 & 1.5431 & 0.0500 \\
\hline 2000 & 41 & 0.2667 & 0.5333 & 0.2000 & 1.5271 & 0.0500 \\
\hline 3000 & 41 & 0.2667 & 0.5333 & 0.2000 & 1.5217 & 0.0500 \\
\hline 4000 & 41 & 0.2667 & 0.5333 & 0.2000 & 1.5191 & 0.0500 \\
\hline 5000 & 41 & 0.2667 & 0.5333 & 0.2000 & 1.5175 & 0.0500 \\
\hline 6000 & 41 & 0.2667 & 0.5333 & 0.2000 & 1.5164 & 0.0500 \\
\hline 7000 & 41 & 0.2667 & 0.5333 & 0.2000 & 1.5156 & 0.0500 \\
\hline 8000 & 41 & 0.2667 & 0.5333 & 0.2000 & 1.5151 & 0.0500 \\
\hline 9000 & 41 & 0.2667 & 0.5333 & 0.2000 & 1.5146 & 0.0500 \\
\hline
\end{tabular}

Table IV: Mean number of customers in the orbit and Mean queue length of high Priority queue for $\lambda_{1}=10 \quad \lambda_{2}=5 \quad \mu_{1}=20 \quad \mu_{2}=25 \quad \mathrm{p}=0.8 \quad \mathrm{q}=0.2 \quad \mathrm{k}=8$ and various values of $\sigma$

\begin{tabular}{|c|c|c|c|c|c|c|}
\hline$\sigma$ & Ocut & $\mathrm{P}_{0}$ & $\mathrm{P}_{1}$ & $\mathrm{P}_{2}$ & $\mathrm{MNCO}$ & $\mathrm{MPQL}$ \\
\hline 10 & 52 & 0.2667 & 0.5333 & 0.2000 & 4.7111 & 0.0500 \\
\hline 20 & 47 & 0.2667 & 0.5333 & 0.2000 & 3.1111 & 0.0500 \\
\hline 30 & 45 & 0.2667 & 0.5333 & 0.2000 & 2.5778 & 0.0500 \\
\hline 40 & 44 & 0.2667 & 0.5333 & 0.2000 & 2.3111 & 0.0500 \\
\hline 50 & 43 & 0.2667 & 0.5333 & 0.2000 & 2.1511 & 0.0500 \\
\hline 60 & 43 & 0.2667 & 0.5333 & 0.2000 & 2.0444 & 0.0500 \\
\hline 70 & 42 & 0.2667 & 0.5333 & 0.2000 & 1.9682 & 0.0500 \\
\hline 80 & 42 & 0.2667 & 0.5333 & 0.2000 & 1.9111 & 0.0500 \\
\hline 90 & 42 & 0.2667 & 0.5333 & 0.2000 & 1.8667 & 0.0500 \\
\hline 100 & 42 & 0.2667 & 0.5333 & 0.2000 & 1.8311 & 0.0500 \\
\hline 200 & 41 & 0.2667 & 0.5333 & 0.2000 & 1.6711 & 0.0500 \\
\hline 300 & 41 & 0.2667 & 0.5333 & 0.2000 & 1.6178 & 0.0500 \\
\hline 400 & 41 & 0.2667 & 0.5333 & 0.2000 & 1.5911 & 0.0500 \\
\hline 500 & 41 & 0.2667 & 0.5333 & 0.2000 & 1.5751 & 0.0500 \\
\hline 600 & 41 & 0.2667 & 0.5333 & 0.2000 & 1.5644 & 0.0500 \\
\hline 700 & 41 & 0.2667 & 0.5333 & 0.2000 & 1.5568 & 0.0500 \\
\hline 800 & 41 & 0.2667 & 0.5333 & 0.2000 & 1.5511 & 0.0500 \\
\hline 900 & 41 & 0.2667 & 0.5333 & 0.2000 & 1.5467 & 0.0500 \\
\hline 1000 & 41 & 0.2667 & 0.5333 & 0.2000 & 1.5431 & 0.0500 \\
\hline 2000 & 41 & 0.2667 & 0.5333 & 0.2000 & 1.5271 & 0.0500 \\
\hline 3000 & 41 & 0.2667 & 0.5333 & 0.2000 & 1.5218 & 0.0500 \\
\hline
\end{tabular}

\begin{tabular}{|l|l|l|l|l|l|l|}
4000 & 41 & 0.2667 & 0.5333 & 0.2000 & 1.5191 & 0.0500 \\
\hline 5000 & 41 & 0.2667 & 0.5333 & 0.2000 & 1.5175 & 0.0500 \\
\hline 6000 & 41 & 0.2667 & 0.5333 & 0.2000 & 1.5164 & 0.0500 \\
\hline 7000 & 41 & 0.2667 & 0.5333 & 0.2000 & 1.5157 & 0.0500 \\
\hline 8000 & 41 & 0.2667 & 0.5333 & 0.2000 & 1.5151 & 0.0500 \\
\hline 9000 & 41 & 0.2667 & 0.5333 & 0.2000 & 1.5147 & 0.0500 \\
\hline
\end{tabular}

\section{CONCLUSIONS}

It is observed from numerical study that Mean number of low priority customers in the orbit decreases as the retrial rate increases, the probabilities for the server being idle, busy are independent on retrial rate. The various special cases discussed in section 7 are particular cases of this research work. This research work can further be extended by introducing various parameters like negative arrival and second optional services.

\section{REFERENCES}

[1] Artalejo, J.R (1999a). A classified bibliography of research on retrial queues, Progress in 1990-1999 Top 7, pp 187-211

[2] Artalejo. J.R(Ed) (1999 b). Accessible bibliography on retrial queues, .Mathematical and Computer Modeling 30, pp 223-233.

[3] Artalejo. J.R (2010), Accessible bibliography on retrial queues Progress in 2000-2009,Mathematical and Computer Modeling Vol 51, pp 1071-1081.

[4] Artalejo J.R, A.N. Dudin and V.I. Klimeno (2001), Stationary analysis of a retrial queue with preemptive repeated attempts, Operations Research Letters, Vol 28 No.4 pp 173-180.

[5] Choi B.D and Park K.K (1990). The M/G/1 retrial queue with Bernoulli schedule. Queueing system 7, No. 2. pp 219-227

[6] Choi B.D and Kulkarni V.G (1992), Feedback retrial queueing system, Queueing and related models, Oxford Statist SciSer., 9, Oxford University Press New York 93-105

[7] Choi. B.D, Y.C. Kim and Y.W. Lee (1998), The M/M/c retrial queue with geometric loss and feedback, Computers and Mathematics with applications, 36, No. 6, pp 41-52

[8] Choi B.D and Y. Chang (1999), Single server retrial queues with priority calls, Mathematical and Computer Modeling, 30, No. 3-4 , pp 7-32

[9] Falin G.I, Artalejo J.R, Martin.M (1993).On the single server retrial queue with priority customers, Queueing systems 14 , pp 439-455

[10] Falin G.I and J.G.C. Templeton (1997), Retrial queues, Champman and Hall, London

[11] Farahmand .K and T. Li (2009), Single server retrial queueing system with loss of customers, Advances and Applications, Vol 11, pp 185-197

[12] Kalyanaraman. R and B.Srinivasan (2004), A Retrial Queueing System with two Types of Calls and 
Geometric Loss, Information and Management Sciences, Volume 15, Number 4, pp. 75-88

[13] Krishnakumar. B, S. Pavai Maheswari,and A.Vijayakumar (2002), The M/G/1 retrial queue with feedback and starting failure, Applied Mathematical Modeling, pp 1057-1075

[14] Latouche. G and V. Ramaswamy(1999), Introduction to Matrix Analytic Methods in Stochastic Modelling, ASA-SIAM Philadelphia
[15] Lee. Y.W, (2005), The M/G/1 feedback retrial queue with two types of Customers, Bulletin of the Koerean Mathematical Society, 42,875-887

[16] Neuts. M.F (1981), Matrix Geometric Solutions in Stochastic Models- An algorithmic Approach, the John Hopkins University Press, Baltomore

[17] Takacs. L (1963), A Single Server Queue with Feedback, Bell Syst. Tech. J., Vol. 42, pp. 505-519. 